\title{
Designing a Web-Based Online Tutoring Application in Palembang City Using the SUS (System Usability Scale) Method
}

\author{
M. Rudi Sanjaya ${ }^{1 *}$ Ariansyah Saputra ${ }^{2}$ Bayu Wijaya Putra ${ }^{1}$ Novita Sari $^{3}$ Rahma \\ Destriani ${ }^{3}$ Muhammad Raihan Udda Rahmany ${ }^{3}$
}

\author{
${ }^{1}$ Internet Programming Laboratory, Faculty of Computer Science, Universitas Sriwijaya, Indonesia \\ ${ }^{2}$ Department of Computer Engineering, Politeknik Negeri Sriwijaya, Indonesia \\ ${ }^{3}$ Student Department of Computer Engineering, Faculty of Computer Science, Universitas Sriwijaya, Indonesia \\ ${ }^{8}$ Corresponding author. Email: m.rudi.sjy@ilkom.unsri.ac.id
}

\begin{abstract}
Nowadays, internet has become a major necessity. Almost all or everyone has used the internet in their daily lives, whether for education, business, entertainment, and others, but humans are much or very dependent on the so-called internet. Where, especially in the city of Palembang, the low level of testing or measurement, this website is rarely used using usability, using usability can measure the level of user satisfaction. The research used a questionnaire using the SUS (System Usability Scale) method. The result of this research is to measure the level of user satisfaction, especially in the city of Palembang. The results of using the SUS method using 100 respondents with 10 question items, the results of the questionnaire research using the SUS (System Usability Scale) method show that the average value of the SUS value conversion is 80.65 .
\end{abstract}

Keywords :Design Web, SUS, Application

\section{INTRODUCTION}

Nowadays, internet has become a major necessity. Almost all or everyone has used the internet in their daily lives, whether for education, business, entertainment, and others, but humans are much or very dependent on the so-called internet.

The internet is a media for presenting information based on a network and can or can be accessed anywhere and anytime at a relatively cheap and simple cost. With the existence of an internet, we will also be able or easier to see the existence of a place by using a computer or a media that presents information connected to the internet. [1]

Internet is a medium for presenting network-based information that can be accessed anywhere at a relatively low cost. With the presence of an internet, we will also find it easier or to see a condition or the existence of a place by using a computer or other media that can access the internet. However, everyone often uses or has ever used the internet in the form of a website, and to design a website it must be in accordance with the wishes of the user. [2]
In designing a web or website, several things must be considered, namely how to make an interface design using usability on a website, namely how far a website can or can be used by users to achieve the goals or objectives expected by or can be said of user satisfaction in designing The website application that will be built and also hopes to attract or help users, connoisseurs or internet users will of course feel comfortable using or building a website. [3]

Along with the development of a technology today, one of the technologies is widely used for promotional facilities and infrastructure in presenting information, especially in the field of designing current websites and also providing information presentation media to offer various conveniences in presenting information media, one of which is the website. In promoting and also marketing, these boutique shops are still used manually and are less efficient, namely by distributing brochures, banners and others. The boutique can be used or utilized as a website as a medium for promotion and information to promote a boutique and also to explain or show that the boutique is of good quality, especially in terms of promotion. In designing a website, namely through the media of presenting 
promotions and presenting information using ves boutique consisting of one or two pages in between, the admin page as managing and the main page as the presentation of promotion. In designing or building this website, consumers or users can place an order for products directly without having to come or visit the boutique. This website is designed to use the PHP and MySql programming languages. [3]

School is the world of education or one of the means of formal education that must be able to provide the best facilities or services, especially for students, including parents. One of the right methods is by utilizing an information technology to access especially academic values in the form of a website. One of the software development methods used is the Waterfall method, in which the design of a web-based academic information system is expected to provide optimal service to students and also parents so that there is no need to come to school to get academic information, so it is expected can produce fast and accurate information. [4]

An Information Technology today has developed very rapidly in a variety of software created to today's modern hardware. Current technological developments or from time to time are more advanced or we can see it in various aspects of life such as one of which is to communicate with people or the outside world by simply using email or other online presentation media or registering school just simply connecting to the internet and can enter to page one of the intended website pages, so that carrying out all the activities that we do or do becomes easier and more efficient. The goal in building a school website, especially in the acceptance of new students, can be through or use an online presentation medium and website. By using the Java programming language, MySQL, and Netbeans 8.1 as media tools or editors. Designing this website can make it easier for prospective students to register for school, just simply connect to the internet, with registration apat or can be done anywhere, anytime. The school is also in carrying out or recording or printing financial reports or printing student acceptance data reports using the website. [5]

In Palembang city, there are a lot of tutoring or tutoring, it is difficult to access and get tutoring information or tutoring, in the city of Palembang a guidance to create or design a web is not tested with a certain method, so doing research to make a design using the SUS (System Usability Scale) method with this method it can be seen whether the design is appropriate with the user or to determine the level of user satisfaction.

\section{OVERVIEW}

\subsection{Designing Web}

Web Design is a general term that is often used to cover how or how to display web content, usually in the form of hypertext or hypermedia which will be sent to end users via the WWW (World Wide Web), using a browser with the aim of designing this web is to create or build a website or a collection of content online including documents, applications that are on the server / web. A web or website can also be a collection of images, text, sound or other content, and can also be interactive or static. [6]

\subsection{Web (World Wide Web)}

Web is a media for presenting information is a medium for presenting information in the form of the internet, using technology in the form of hypertext, users or users are led to find or display media information by following links that have been provided in web documents and then displayed in a web browser. [7]

Website is a method for displaying information media, one of which is the internet, whether it is in the form of text, images, video and sound or an interactive one that has the advantage of connecting, namely links from documents to other documents or (hypertext) which can be accessed via a browser. [8]

\subsection{Tutoring (BIMBEL)}

Tutoring is a process for providing information presentation, especially assistance from tutors to students or students in a way or can develop a learning atmosphere that is conducive and also to cultivate an ability so that students can avoid or be able to overcome obstacles or difficulties in learning which may be faced so as to achieve good learning outcomes.

Tutoring is a form of activity in carrying out the learning process carried out or carried out by someone who has the ability or more in many ways to be given to others with the aim that other people can or are able to find out about new knowledge that they don't have and can also to be applied in his life and also this tutoring is connected to the internet. [9] 


\subsection{Kriteria Metode $S$}

The method of criteria for the SUS method is described below:

Table 1. Criteria of SUS Method

\begin{tabular}{|l|l|l|}
\hline SUS & Grade & Adjective Rating \\
\hline$>=80,3$ & A & Excellent \\
\hline $68-80,3$ & B & Good \\
\hline 68 & C & Okay \\
\hline $51-68$ & D & Poor \\
\hline$<51$ & F & Awful \\
\hline
\end{tabular}

In table 1 , it is explained the criteria of SUS until it reaches above> 80.3 Very good, but the lowest value $<51$ results in an Awful value. [10]

\section{RESEARCH METHODOLOGY}

This research method uses SUS (System Usability Scale), data collection uses a questionnaire consisting of 100 respondents and has 10 questions and will be tested using the SUS (System Usability Scale) method. [11], by using this method can measure the level of user satisfaction in the SUS questionnaire application design using a Likert scale

\subsection{Data Analysis}

Data were collected throughonline zoom with 100 respondetns from 10 questions regarding design using the SUS (System Usabillty Scale) method.

\subsection{Software Development Methods}

The development of this software development method is the Prototype Model. Here is the Prototype Model

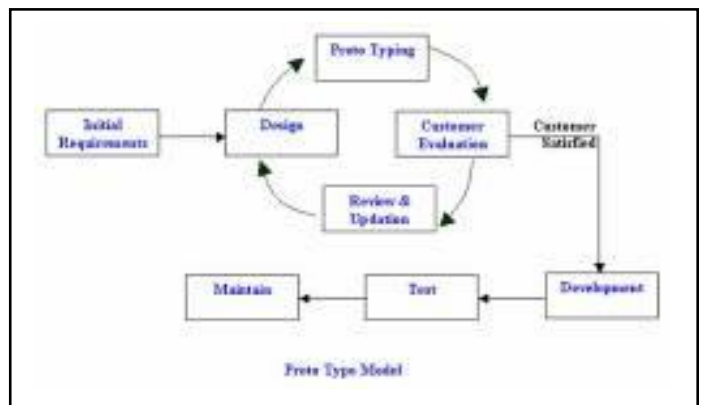

Figure 1. Prototype Model

The stages in Prototyping are as follows.:

1. Collection of needs is Customers and developers together define the format of the entire software, identify all requirements, and an outline of the system to be made.

2. Build Prototyping

Build Prototyping by making temporary designs that focus on serving customers (for example, by creating input and output formats).

3. Evaluation of prototyping

This evaluation is carried out by the customer, whether the Prototyping that has been built is in accordance with the customer's wishes. Otherwise, Prototyping is revised by repeating.

4. Encoding the system

In this stage, the Prototyping that has been agreed upon is translated into the appropriate programming language.

5. Test the system

After the system has become a ready-to-use software, it must be tested before use. This test is carried out by SUS testing

6. System Evaluation

Customers evaluate whether the finished system is as expected.

7. Using the system

Software that customers have tested and accepted is ready to use.

\section{USE CASE ADMIN}

\subsection{Use case Admin}

Figure 2 Use case admin in the software describes the data foundation and is submitted to the user (student).

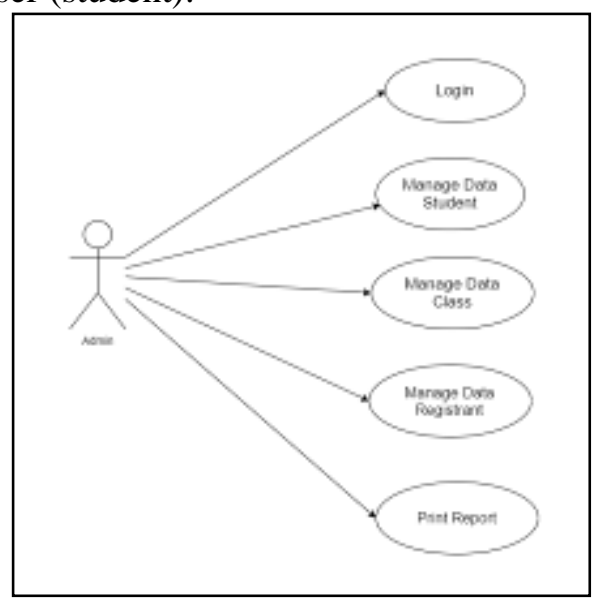

Figure 2. Use Case Admin 
Figure 2 use case admin explains about all data will be processed and will be managed by admin

\subsection{Use case User}

Figure 3 use case user can be seen below:

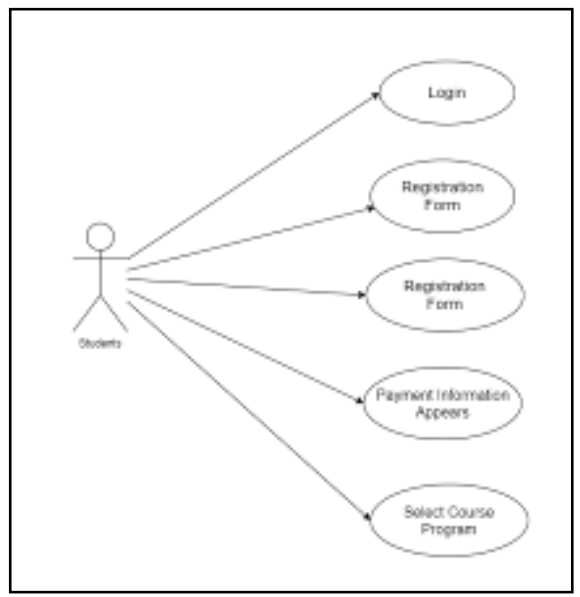

Figure 3. Use Case Student

Figure 2 explains use case student only can see the data and also print the report.

\subsection{Use Case Owner}

Figure 3 use case owner

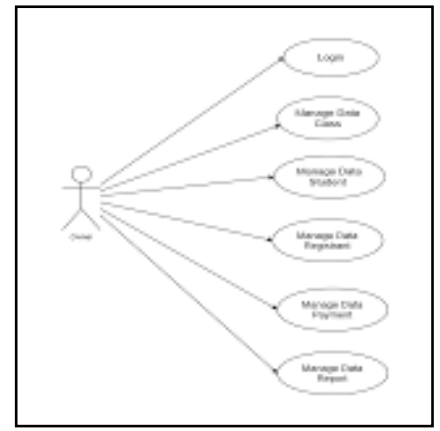

Figure 3. Use Case Owner

Figure 3 use case owner manage all data and control data incoming data and outgoing data.

\section{RESULTS}

\subsection{Application Design}

\subsubsection{Home Page Design}

Web design in home page can be seen in figure 4

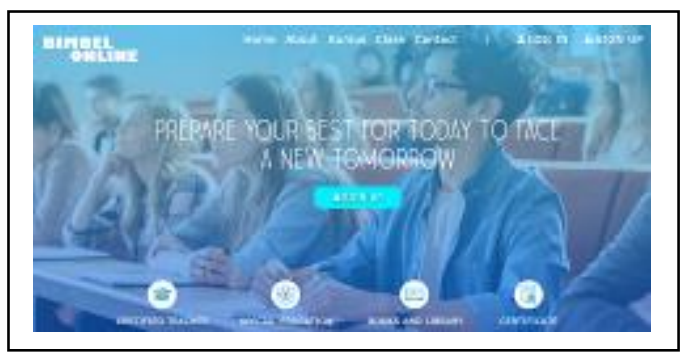

Figure 4 explains the menu containing the main page, a description of tutoring, course program, class program, class schedule, contact person, and login page. The home page design image.

\subsubsection{Login Form Display Design}

In the user login form, you can see the image below:

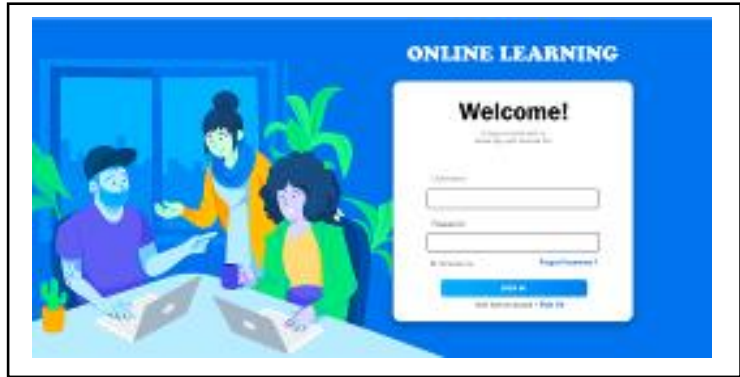

Figure 5 explains to fill in the username and password that matches the username and password in the database. If you don't have access to log in, the User is welcome to register or sign up first.

\subsubsection{Class Page Design}

In this page can be seen below:

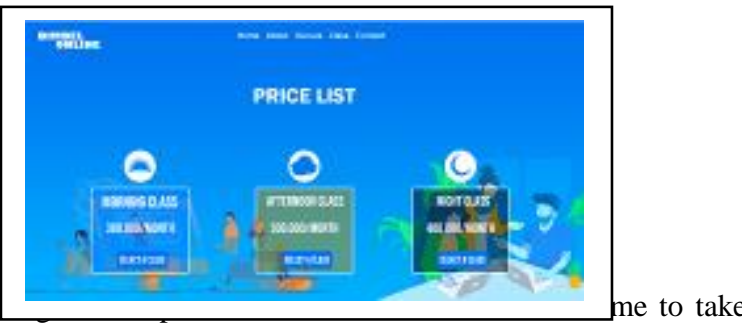

classes, class schedules and class programs and tuition prices per month.

\subsubsection{Admin Login Page Design}

Admin Login page is the first form, can be seen in the image below:

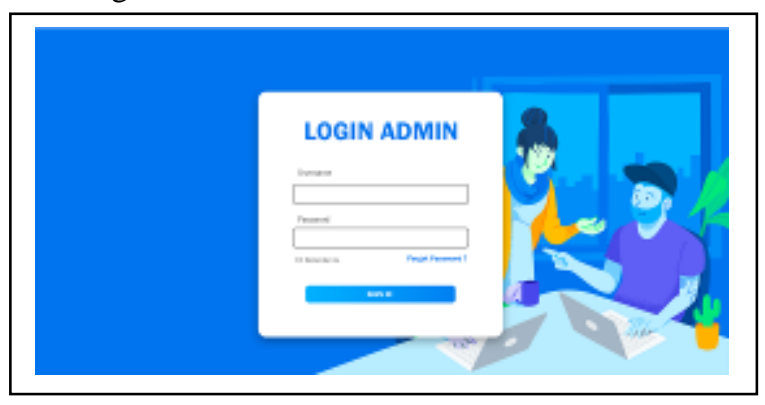

Figure 7 Admin Login Page

Figure 5, In the login form the admin is required to $\log$ in first by filling in the username and password that matches the username and password in the database.

Figure 4. Home Page 


\subsubsection{Admin Home Page Design}

The web design on the admin home page can be seen below :

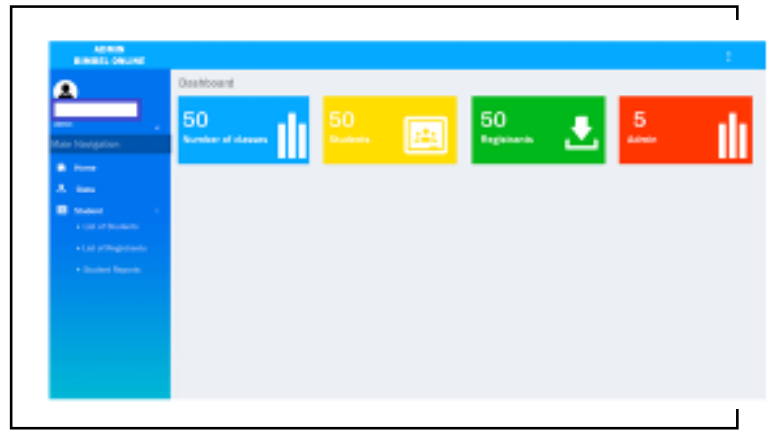

Figure 8. Admin Home Page

Figure 8 has a dashboard display in the form of class totals, total students, total registrants and total admins. As well as having main menus such as Class and Students.

\subsubsection{Admin Class Menu Page Design}

Page design in the Class menu, Admin can add,

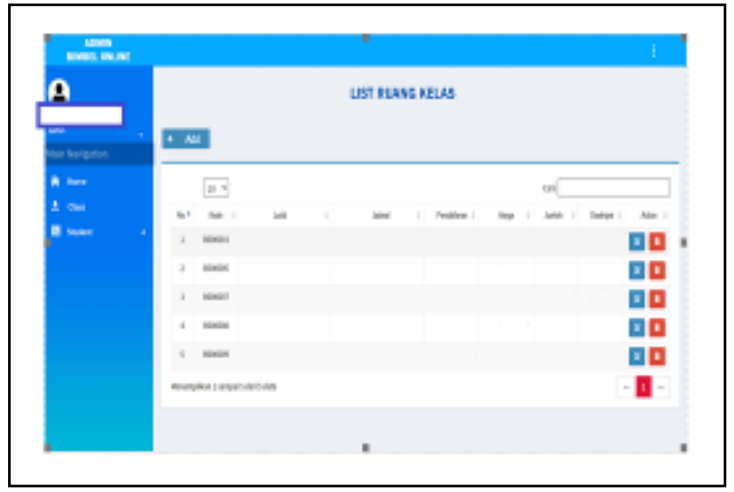

Figure 9. Class Menu Page Design

Figure 9 explains removing and editing class code, class programs, class schedules, fees registration, class time, price per month, and class description

\subsubsection{Admin Student Menu Page Design (Student List)}

This page is used to view student data :

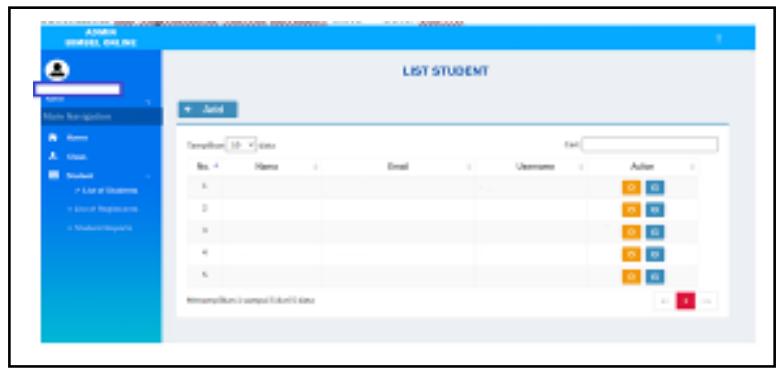

Figure 10. Admin Student Menu Page Design (Student List)
Figure 7. is completed with the student's full name, student e-mail address, student username. Admin also can edit student biodata if students make mistakes in filling out the data.

\subsubsection{Rancangan Halaman Menu Siswa (List Pendaftar)}

This page serves to view the registrant list data

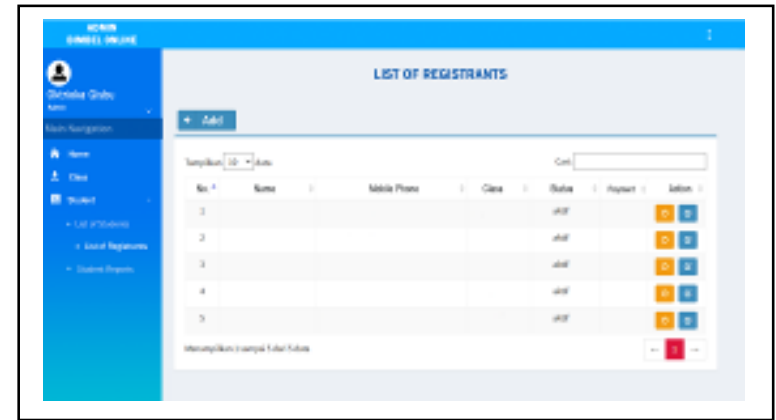

Figure 11. Student Menu Page Design (List of Registrants)

Figure 11 explains the form of name, cellphone number, class, registrant status, payment and admin can delete and view registrant detail data and registrant payment status. And Figure 9 Design of Student Menu Pages (Student Report)

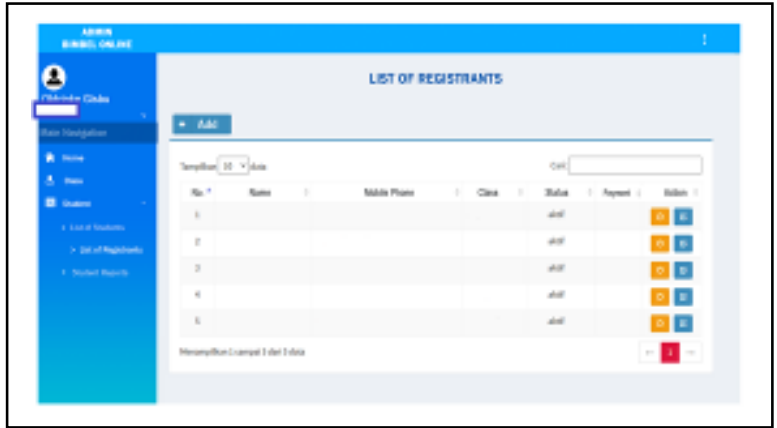

Figure 12. Student Menu Page Design

Figure 9 explains that this page is used to print and recap student data that can be filtered based on the desired date, month, and year. Student reports can be printed via Excel, CSV, Pdf and also copied.

\section{DISCUSSION}

\subsection{The SUS (System Usability Scale) Method}

The research method used SUS (System Usability Scale), data collection used a questionnaire consisting of 100 respondents and had 10 questions with 5 answer choices from 0 to 4 with the following questions:

P1. I think I want to use the website often

$\mathrm{P} 2$. I found a simple website 
P3. I think this website is easy to use

P4. I think I can use this website without technician support

P5. I found the various functions on the website were well integrated

P6. I think there is a lot of consistency on the website P7. I imagine that most people will learn to use websites very quickly

P8. I found the website very intuitive

Q.9 I feel very confident about using this website

Q.10 I can use the website without learning anything new

To get the average value of SUS, it is calculated to calculate the SUS value by analyzing the results of the respondent with an odd value, then the value is subtracted by 1 . For the result of the respondent having an even value, the value of 5 is deducted by the result of the respondent. From the analysis of the results of the SUS questionnaire shows that the average value of the SUS value conversion results is 80.65 .

The results of the SUS questionnaire can be seen in

Figure 10. It can be taken that P2 and P8 got the highest results. The questions that received the highest response were "I found the website simple" and

"I found the website very intuitive".

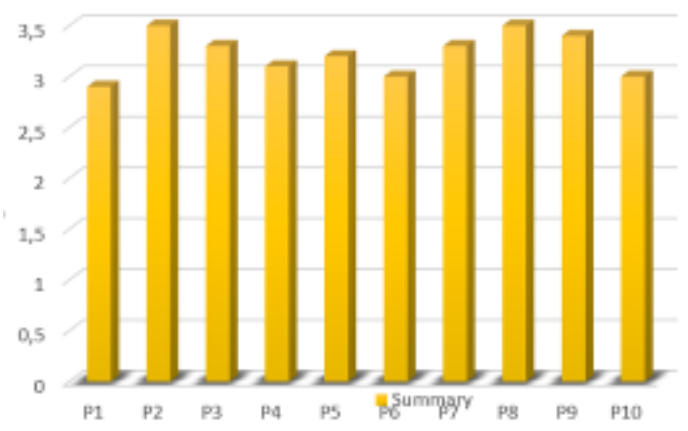

Figure 13. Result

\section{CONCLUSION:}

1. This design is made according to user needs, especially in the city of Palembang, which is done using the SUS method, the average value of SUS is 80.65 or categorized as very good. The questions that received the highest response were "I found the website simple" and "I find the website very intuitive".

2. This study uses the SUS method with 100 respondents and 10 questions, the results of the questionnaire research using the SUS (System Usability Scale) method indicate that the average value of the SUS value conversion is 80.65 .

\section{REFERENCES}

[1]

[11] A. W. Soejono, A. Setyanto, and A. F. Sofyan, "Evaluasi Usability Website UNRIYO Menggunakan System Usability Scale (Studi Kasus: Website UNRIYO)," J. Teknol. Inf., 2018. 